\title{
Perbandingan Metode Breadth First Search dan Backlink pada Web Crawler
}

\author{
JASMAN PARDEDE, ASEP NANA HERMANA, GALIH SWARGHANI
}

Teknik Informatika, Fakultas Teknologi Industri

Email : jasmanpardede78@gmail.com

\begin{abstract}
ABSTRAK
Dalam sebuah search engine terdapat beberapa komponen penting yang salah satunya adalah crawler / web crawler. Crawler adalah sebuah komponen dalam search engine yang berfungsi untuk mencari semua link pada setiap halaman dimana hasil pengumpulan alamat web selanjutnya akan diindeks. Crawler bekerja dengan menggunakan algoritma pencarian yang beragam, diantaranya adalah Breadth First Search dan Backlink. Breadth first search merupakan algoritma untuk melakukan pencarian secara berurutan dengan mengunjungi setiap simpul secara preorder. Backlink memanfaatkan tautan yang berada disitus lain dan mengarah ke situs tertentu. Adapun hasil dari uji aplikasi yaitu dengan membandingkan kedua metode tersebut dengan cara melihat performa pengambilan URL terbanyak pada Detik.com dan Kompas.com. Metode breadth first search secara performa lebih baik dibandingkan dengan metode backlink, dalam pengujian crawling, perbedaan jumlah url mencapai 25,17 pada website detik.com dan 28,94\% pada website Kompas.com.
\end{abstract}

Kata kunci: Web Crawler, Breadth First Search, Backlink.

\begin{abstract}
In a search engine, there are several important components, one of which is a crawler / web crawler. Crawler is a component in the search engine used to find all the links on each page and then collecting the results will then be indexed web address. Crawler works by using search algorithms are diverse, including the Breadth First Search and backlinks. Breadth first search is an algorithm to do the search berurutandengan visiting each node in a preorder. While backlinks utilize our site link contained another and leads to a specific site. The results of the test application is by comparing the two methods by looking at the URL retrieval highest performance on Detik.com and Kompas.com. Breadth first search method is a better performance than the backlink methods, in testing crawling, different numbers on the website url detik.com reached 25.17 and $28.94 \%$ in Kompas.com website.
\end{abstract}

Keywords: Web Crawler, Breadth First Search, Backlink. 


\section{PENDAHULUAN}

Search engine atau dalam secara istilah disebut mesin pencari merupakan sebuah sistem yang memungkinkan pengguna untuk mencari data di internet hanya dengan mengetikan sebuah kata kunci (keyword). Dalam sebuah search engine terdapat beberapa komponen penting yang salah satunya adalah crawler / web crawler. Crawler dalam sebuah search engine berfungsi untuk mencari semua link pada setiap halaman. Web crawler melakukan tiga yaitu proses scraping, parsing dan indexing. Proses scraping dibantu menggunakan library jsoup pada saat proses scraping berlangsung. Proses parsing yaitu proses saat pemisahan kata atau kode berdasarkan element yang sudah ditentukan. Hasil pengumpulan situs web selanjutnya akan di index. Proses indexing yaitu dengan melakukan split berdasarkan tanda "/". Indexing dilakukan untuk menentukan judul berita, dan melakukan pengelompokkan terhadap data yang sudah didapatkan berdasarkan alur metode. Crawler bekerja dengan menggunakan algoritma pencarian yang beragam, diantaranya adalah Breadth First Search dan Backlink. Pengimplementasian web crawler pada penelitian ini dilakukan dengan cara membandingkan dua metode yaitu Breadth First Search (BFS) dengan Backlink untuk melakukan pencarian dan pengarsipan pada sebuah website.

Breadth First Search merupakan algoritma yang melakukan pencarian secara berurutan dengan mengunjungi setiap simpul secara preorder. Backlink memanfaatkan tautan yang berada disitus lain dan mengarah ke situs tertentu. Inti dari penelitian ini adalah merancang sebuah aplikasi yang memanfaatkan konsep crawler untuk melakukan pencarian artikel pada sebuah situs tertentu dan membandingkan hasil penerapan dari kedua konsep algoritma pencarian untuk mengetahui mana yang lebih handal.

\section{METODOLOGI PENELITIAN}

Web crawler diaplikasikan sebagai sistem pengarsipan berupa alamat web, judul berita dan konten artikel dari web yang di crawling. Web crawler memiliki tiga proses pada saat melakukan crawling, yaitu proses pembacaan halaman (scraping), proses pemisahan kata (parsing), dan proses pengindeksan (indexing). Hasil akhir web crawler di implementasikan sebagai sistem pengarsipan berupa alamat web, judul berita, dan konten artikel. Proses crawler ini dilakukan pada website Detik.com dan Kompas.com.

Proses scraping merupakan proses paling awal saat melakukan crawling untuk mendapatkan html berdasarkan input objek yang diingin kan user. Penguraian dilakukan berdasarkan method yang digunakan dalam penentuan setiap tag html, body dan head, dengan pembacaan "<" dan">". Pembacaan berdasarkan tag html, dimana pada halaman web yang berupa sekumpulan kode dibaca sesuai dengan penguraian tag html, head dan body.

Proses parsing merupakan proses kedua dalam melakukan crawling proses tersebut yaitu pemisahan kata untuk menentukan sebuah element yang diambil. Element yang diambil yaitu element "a href" untuk pengambilan link. Selanjutnya setelah ditentukan sebuah element untuk pemisahan, maka setiap pemisahan kata dilakukan berdasarkan element tersebut.

Proses pengambilan data pada kata yang telah dipisah berdasarkan element "a href":

$<$ a href= "https://news.detik.com/berita/d-3379142/bnpb-banjir-kembali-terjadi-di-ntb" $>$

Hasil proses parsing: 


\section{https://news.detik.com/berita/d-3379142/bnpb-banjir-kembali-terjadi-di-ntb}

Proses indexing merupakan proses terakhir dalam melakukan crawling, dan proses dimana metode breadth first search dan backlink diterapkan. Pada indexing dilakukan split terhadap web yang sedang di crawl, split yang dilakukan berupa pemisahan tanda "/". Kemudian sistem melakukan pengecekkan kata yang telah di split. Pengecekkan kata dari tahap splitting, untuk menentukan judul berita, dan dilakukan pengelompokan berdasarkan alur metode breadth first search dan backlink.

Breadth first search crawling menguji tiap link pada sebuah halaman sebelum memproses ke halaman berikutnya. Jadi, algoritma ini menelusuri tiap link pada halaman pertama dan kemudian menelusuri tiap link pada halaman pertama pada link pertama dan begitu seterusnya sampai tiap level pada link telah dikunjungi [2]. Saat melakukan crawling menggunakan pengurutan berdasarkan backlink, maka pada saat mengunjungi halaman web, setiap hyperlink yang ada dilihat merujuk ke halaman web yang mana. Kalau halaman web yang dirujuk belum ada di list, maka halaman tersebut dimasukkan ke dalam list dan backlinknya diberi nilai $1[2]$.

Proses penerapan breadth first search dan backlink dalam indexing memerlukan kebutuhan data utnuk membantu saat proses crawling dengan breadth first search dan backlink. Kebutuhan data diperoleh dari website Kompas.com dan Detik.com, dengan didapatkan kesimpulan, yaitu :

1. Data kode judul, berupa inisialisasi kode yang digunakan untuk penentuan judul yang diambil dari kata atau bagian terakhir pada alamat web yang setiap kata atau bagiannya dipisah oleh "/" seperti yang ditampilkan pada Gambar 1.

2. Data element konten artikel yang ditampilkan pada Tabel 1, merupakan sebuah element yang digunakan untuk proses pengambilan artikel. Penentuan element ini ditentukan berdasarkan sebuah element yang menjadi wadah untuk konten artikel yang dimiliki oleh website yang menjadi objek utama.

3. Data Atribut Rel pada backlink yang ditampilkan pada Tabel 2, merupakan sebuah kode untuk mendapatkan URL backlink, penentuan atribut ini ditentukan berdasarkan sebuah element yang menjadi wada untuk penentuan URL yang dapat mengakses URL root.

nasional.kompas.com/read/2016/12/14/16155321/transparansi.pengadaan.alutsista

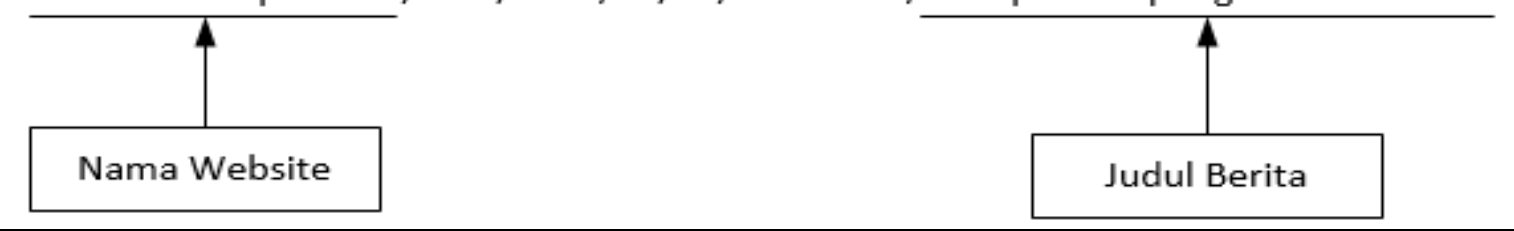

Gambar 1/ Kode Judul Berita 
Tabel 1. Data Element Konten Artikel

\begin{tabular}{|c|l|c|}
\hline No & Alamat Web & Element Konten Artikel \\
\hline 1. & Kompas.com & div.kcm-read-text \\
\hline 2. & Detik.com & div.text_detail \\
\hline
\end{tabular}

Tabel 2 Data atribut backlink

\begin{tabular}{|c|l|l|}
\hline No & Alamat Web & Atribut Backlink \\
\hline 1. & Kompas.com & Rel ="dofollow" \\
\hline 2. & Detik.com & Rel ="dofollow" \\
\hline
\end{tabular}

\section{ANALISIS DAN PEMBAHASAN}

Indexing web crawler yang dibangun dilakukan dengan dua cara yaitu dengan metode breadth first search dan backlink. Pada metode breadth first search dan backlink dilakukan proses dimana sistem mengambil element dari URL root untuk pengambilan URL. Sistem mengambil semua atribut "href" untuk mendapatkan URL pada alamat web dan melakukan pengecekan link. Jika pada saat pengecekkan link terdapat duplikasi, maka link yang didapat akan dilewati oleh sistem dan melakukan kembali pengecekkan link. Jika pada alamat web tidak terdapat link lagi, sistem melanjutkan ke proses pengumpulan data berupa URL, judul berita dan konten artikel. Dan jika masih ada link yang harus dikunjungi, maka sistem melakukan proses breadth first search atau backlink kembali.

Pengecekan link berupa pencocokkan link yang sudah diambil dengan link root. Proses terakhir untuk breadth first search yaitu sistem menampilkan URL yang diambil berdasarkan urutan pengambilan dari alur breadth first search. Sedangkan proses terakhir untuk backlink yaitu sistem menampilkan URL backlink yang berupa URL yang mengandung rel "dofollow" yang berarti URL tersebut adalah URL backlink.

Pada alur kerja web crawler terdapat 3 proses tahapan, yaitu:

Proses web crawler ini yaitu proses crawling secara keseluruhan dari mulai sistem terkoneksi dengan library (jsoup) untuk memulai proses pembacaan parameter html pada halaman web, membaca halaman web semua parameter html yang ada pada suatu halaman web, dan pada proses terakhir melakukan proses parsing menggunakan metode breadth first search dan backlink, yang dimana hasilnya ditampilkan berupa URL, judul berita dan konten artikel. 


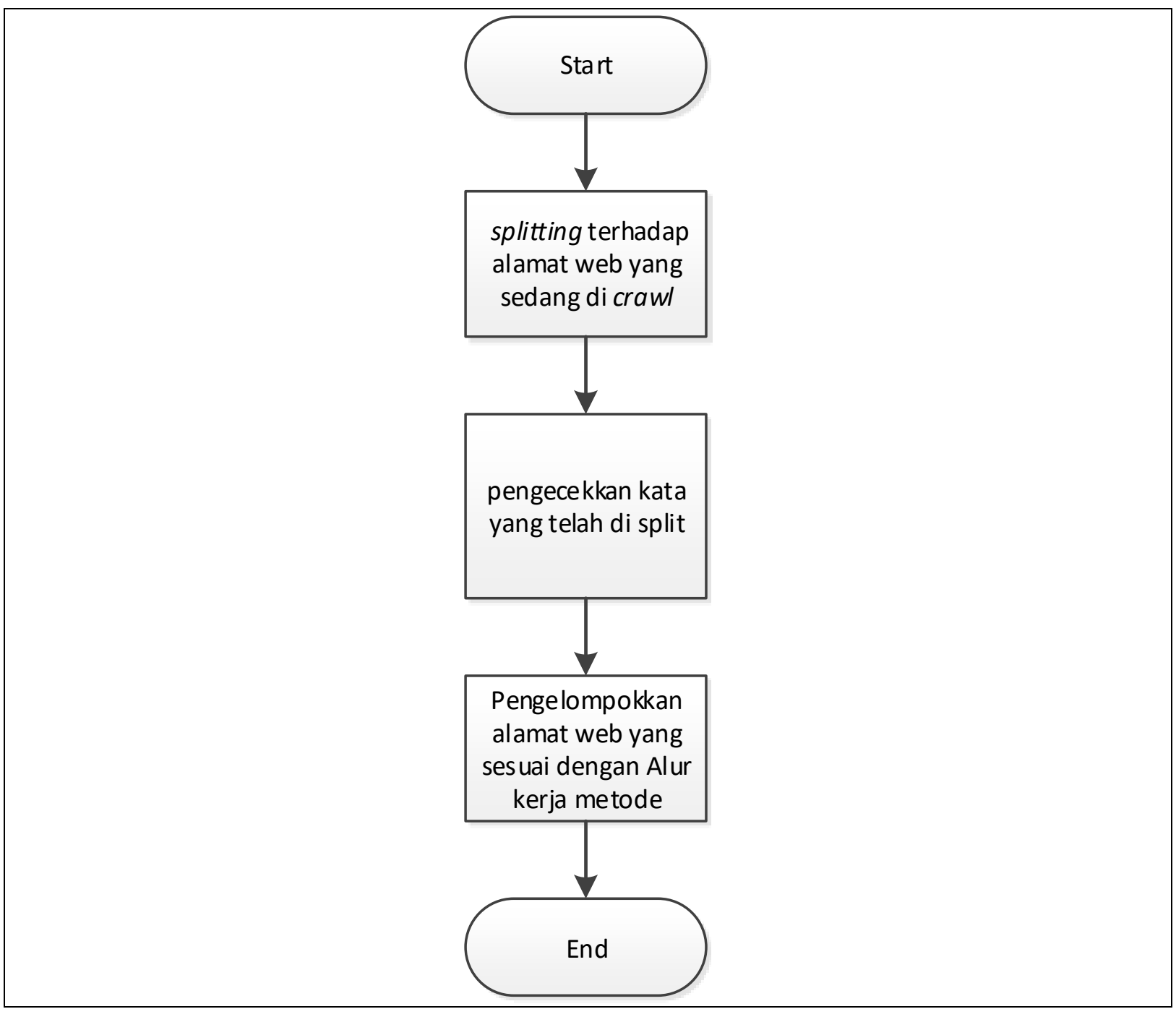

\section{Gambar 4. Flowchart Proses Indexing}

Pada proses indexing dilakukan 3 tahapan, yaitu :

1. Melakukan spliting terhadap web yang sedang di crawl, split yang dilakukan berupa pemisahan tanda " $/$ ".

Hasil parsing berupa sekumpulan alamat web:

1. https://news.detik.com

2. https://finance.detik.com

3. https://hot.detik.com

4. https://inet.detik.com

5. https://facebook.com

2. Pengecekkan kata yang telah di split. Pada tahap ini, dilakukan pengecekkan kata dari tahap splitting, untuk menentukan judul berita, berdasarkan alur metode breadth first search dan backlink. 
Tahap pengecekkan alamat web:

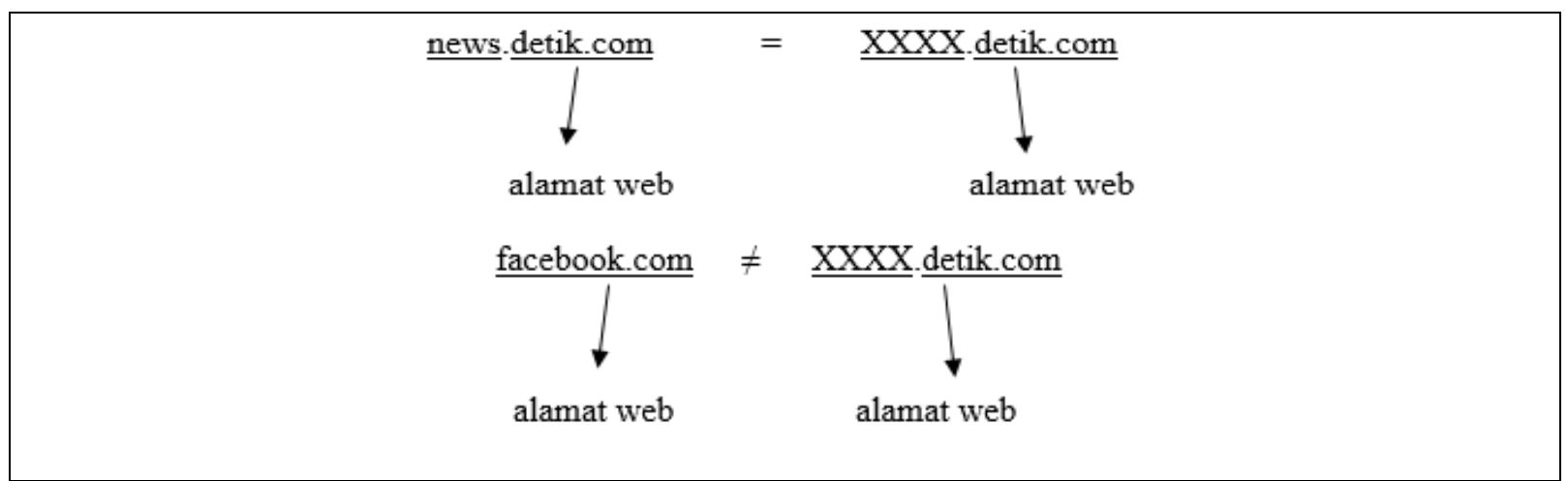

\section{Gambar 5. pengecekksn alamat web}

3. Tahap terakhir, dilakukan pengelompokkan hasil crawl yang telah diambil berdasarkan dengan alur setiap metode.

Tahap pengelompokkan alamat web:

1. https://news.detik.com

2. https://finance.detik.com

3. https://hot.detik.com

4. https://inet.detik.com

5. https://facebook.com

Hasil indexing pada alamat web breadth first search:

1. https://news.detik.com

2. https://finance.detik.com

3. https://hot.detik.com

4. https://inet.detik.com

Pada proses indexing dengan menggunakan metode breadth first search yaitu pengelompokkan berdasarkan alur breadth first search yaitu pengambilan URL secara berurutan.

Tahap parsing alamat web dengan backlink:

$\begin{array}{lll}\text { 1. https://news.detik.com } & \text { match } & \text { dofollow } \\ \text { 2. https://finance.detik.com } & \text { match } & \text { dofollow } \\ \text { 3. https://hot.detik.com match } & \text { dofollow } \\ \text { 4. https://inet.detik.com match } & \text { dofollow } \\ \text { 5. https://facebook.com not match } & \text { nofollow }\end{array}$

Tahap pengelompokkan alamat web:
1. https://news.detik.com
match
dofollow
2. https://finance.detik.com
match
3. https://hot.detik.com match
dofollow
4. https://inet.detik.com match
dofollow
5. https://facebook.com not match dofollow nofollow 
Hasil indexing pada alamat web backlink:

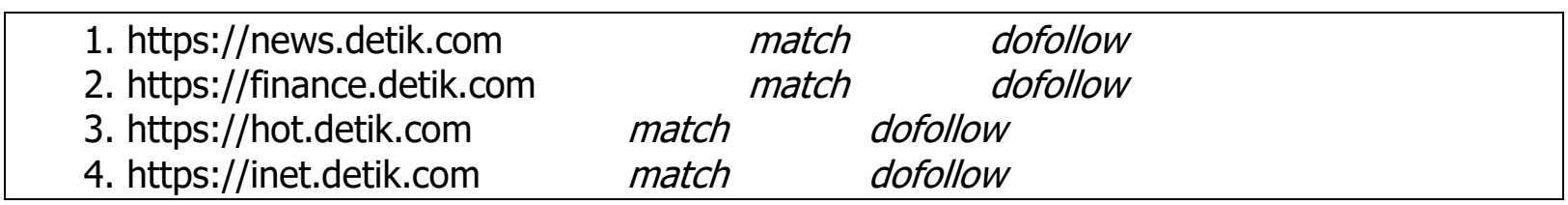

Hasil proses indexing dengan breadth first search dan backlink adalah hasil pengelompokkan berdasarkan alur metode breadth first search dan backlink. Pengelompokkan berdasarkan breadth first search yaitu berdasarkan URL yang pertama kali diambil oleh web crawler dan secara berurut sampai URL terakhir diambil. Pada backlink pengelompokkan berdasarkan URL yang mengandung rel "dofollow". Sehingga dapat dilihat perbedaan pengambilan pada kedua metode.

\section{Skenario Pengujian}

Pengujian yang dilakukan terdiri dari 2 aspek, yaitu pengujian unjuk kerja pengambilan URL dengan menggunakan metode breadth first search dan backlink pada website Detik.com dan Kompas.com dengan kecepatan internetnya 2,5Mbps kondisi tidak stabil. Dan pengujian duplikasi terhadap data yang sudah di crawl.

\subsection{Pengujian Web Crawler Breadth First Search dan Backlink}

Pada tahap ini, merupakan hasil pengujian yang dilakukan untuk melihat kinerja dari web crawler. Penilaian kinerja tersebut dilihat berdasarkan jumlah URL yang terambil yang dilakukan web crawler dalam satu kali proses.

a. Pengujian Performansi

Tabel 3. Perbandingan Breadth First Search dan Backlink pada Web Detik.com

\begin{tabular}{|c|c|c|c|c|c|}
\hline \multirow[t]{2}{*}{ Pengujian } & \multirow[t]{2}{*}{ Alamat web } & BFS & Backlink & \multirow{2}{*}{$\begin{array}{c}\text { Pada } \\
\text { Tanggal }\end{array}$} & \multirow[t]{2}{*}{ Jam } \\
\hline & & $\begin{array}{c}\text { Banyaknya } \\
\text { URL }\end{array}$ & $\begin{array}{c}\text { Banyaknya } \\
\text { URL }\end{array}$ & & \\
\hline 1 & Detik.com & 1103 url & $884 \mathrm{url}$ & 29/12/2017 & $08.00 \mathrm{WIB}$ \\
\hline 2 & Detik.com & 982 url & $637 \mathrm{url}$ & $29 / 12 / 2017$ & $08.30 \mathrm{WIB}$ \\
\hline 3 & Detik.com & $876 \mathrm{url}$ & 710 url & 29/12/2017 & $09.15 \mathrm{WIB}$ \\
\hline 4 & Detik.com & 1022 url & 683 url & 29/12/2017 & $09.30 \mathrm{WIB}$ \\
\hline 5 & Detik.com & 994 url & $721 \mathrm{url}$ & $29 / 12 / 2017$ & 10.00 WIB \\
\hline 6 & Detik.com & 926 url & $821 \mathrm{url}$ & 29/12/2017 & $15.00 \mathrm{WIB}$ \\
\hline 7 & Detik.com & 899 url & 728 url & 29/12/2017 & $15.30 \mathrm{WIB}$ \\
\hline 8 & Detik.com & 1023 url & $637 \mathrm{url}$ & 29/12/2017 & $16.00 \mathrm{WIB}$ \\
\hline 9 & Detik.com & 1078 url & 790 url & 29/12/2017 & $16.30 \mathrm{WIB}$ \\
\hline 10 & Detik.com & 855 url & $690 \mathrm{url}$ & 29/12/2017 & $17.00 \mathrm{WIB}$ \\
\hline
\end{tabular}


Tabel 4. Perbandingan Breadth First Search dan Backlink pada Web Kompas.com

\begin{tabular}{|c|l|c|c|c|c|}
\hline Pengujian & Alamat Web & $\begin{array}{c}\text { BFS } \\
\text { Banyaknya } \\
\text { URL }\end{array}$ & $\begin{array}{c}\text { Backlink } \\
\text { Banyaknya } \\
\text { URL }\end{array}$ & $\begin{array}{c}\text { Pada } \\
\text { Tanggal }\end{array}$ & Jam \\
\hline 1 & Kompas.com & 987 url & 544 url & $29 / 12 / 2017$ & 18.00 WIB \\
\hline 2 & Kompas.com & 844 url & 632 url & $29 / 12 / 2017$ & 18.30 WIB \\
\hline 3 & Kompas.com & 934 url & 722 url & $29 / 12 / 2017$ & 19.15 WIB \\
\hline 4 & Kompas.com & 901 url & 642 url & $29 / 12 / 2017$ & 19.30 WIB \\
\hline 5 & Kompas.com & 877 url & 582 url & $29 / 12 / 2017$ & 20.00 WIB \\
\hline 6 & Kompas.com & 823 url & 782 url & $29 / 12 / 2017$ & 20.30 WIB \\
\hline 7 & Kompas.com & 1015 url & 689 url & $29 / 12 / 2017$ & 21.00 WIB \\
\hline 8 & Kompas.com & 966 url & 772 url & $29 / 12 / 2017$ & 21.30 WIB \\
\hline 9 & Kompas.com & 1106 url & 589 url & $29 / 12 / 2017$ & 22.00 WIB \\
\hline 10 & Kompas.com & 867 Url & 668 url & $29 / 12 / 2017$ & 22.30 \\
& & & & & WIB \\
\hline
\end{tabular}

Tabel 5. Pengujian Pengulangan Data Crawl Kompas.com dan Detik.com

\begin{tabular}{|c|c|c|}
\hline No & Detik.com & Kompas.com \\
\hline 1 & Tidak ada pengulangan & Tidak ada pengulangan \\
\hline 2 & Tidak ada pengulangan & Tidak ada pengulangan \\
\hline 3 & Tidak ada pengulangan & Tidak ada pengulangan \\
\hline 4 & Tidak ada pengulangan & Tidak ada pengulangan \\
\hline 5 & Tidak ada pengulangan & Tidak ada pengulangan \\
\hline 6 & Tidak ada pengulangan & Tidak ada pengulangan \\
\hline 7 & Tidak ada pengulangan & Tidak ada pengulangan \\
\hline 8 & Tidak ada pengulangan & Tidak ada pengulangan \\
\hline 9 & Tidak ada pengulangan & Tidak ada pengulangan \\
\hline 10 & Tidak ada pengulangan & Tidak ada pengulangan \\
\hline
\end{tabular}

\section{KESIMPULAN}

Berdasarkan pengujian yang dilakukan, didapatkan kesimpulan metode breadth first search secara performa lebih baik dibandingkan dengan metode backlink untuk diterapkan pada web crawler. Jumlah URL hasil crawling metode breadth first search pada website Detik.com lebih banyak sebesar $25,17 \%$ dari backlink. Sedangkan pada website Kompas.com metode breadth first search mendapatkan URL lebih banyak sebesar 28,94\% dari backlink, dan pengujian pengulangan data aplikasi web crawler breadth first search dan backlink tidak terdapat pengulangan data.

\section{DAFTAR RUJUKAN}

[1] Yusuf, Muhammad. "Apa itu Web Crawler". Muhammad Yusuf Gunadarma. 2012. Web. 23 Oktober 2016.

[2] Sulastri dan Eri Zuliarso, 2010 Aplikasi Web crawler Berdasarkan Breadth First Search dan Back-Link 
[3] Kustanto, Cynthia, Mutia S, Ratna, Viqarunnisa, Pocut, "Penerapan Algoritma Breadthfirst Search dan Depth-first Search Pada FTP Search Engine for ITB Network", Teknik Informatika, Institut Teknologi Bandung, Bandung.

[4] Munir, Rinaldi. Strategi Algoritmik Diktat Kuliah IF2251. Program Studi Teknik Informatika, Sekolah Teknik Elektro dan Informatika, institut Teknologi Bandung, bandung. 2006.

[5] Maslucha Dewi, 2015 Makalah Algoritma Breadth First Search.

[6] Budi Yuwono, Savio L. Y. Lam, Jerry H.Ying, Dik L. Lee, 1996, A World Wide Web Resource Discovery System, in Proceedings of ICDE.

[7] Zebua, Javier., 2010, Aplikasi Pencarian Buku Berbasis Web Semantik Untuk Perpustakaan SMK Yadika 7 Bogor , UniversitasGunadarma. 